\title{
Assessment of Knowledge, Attitude, and Practice toward COVID-19 among a Sample of Iranian General Population
}

\author{
Heshmatollah Nourmoradi ${ }^{1,2}$, Farogh Kazembeigi ${ }^{2,3}$, Hojatollah Kakaei ${ }^{4}$, Mohsen Jalilian ${ }^{5}$, Amin Mirzaei $^{5 *}$ \\ ${ }^{1}$ Biotechnology and Medicinal Research Center, Ilam University of Medical Sciences, Ilam, Iran; ${ }^{2}$ Department of Environmental \\ Health Engineering, School of Health, Ilam University of Medical Sciences, Ilam, Iran; ${ }^{3}$ Department of Environmental \\ Engineering, School of Environment, Tehran University, Tehran, Iran; ${ }^{4}$ Department of Occupational Health Engineering, School \\ of Health, Ilam University of Medical Sciences, Ilam, Iran; ${ }^{5}$ Department of Public Health, School of Health, Ilam University of \\ Medical Sciences, Ilam, Iran
}

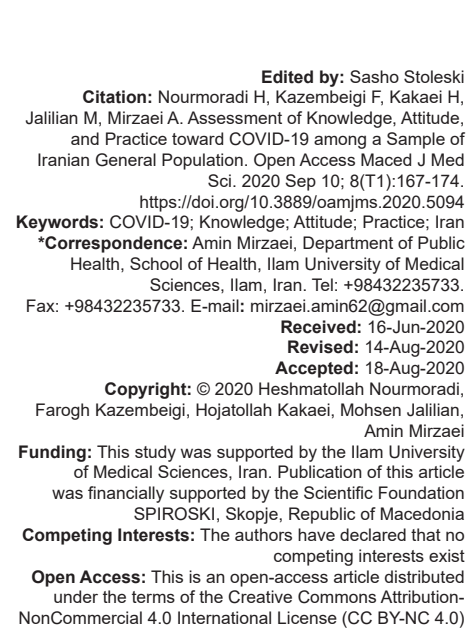

\section{Introduction}

The outbreak of the new coronavirus (SARS-CoV-2) was first reported in December 2019 in Wuhan, the capital of Hubei Province, China [1], [2]. In late 2019, the World Health Organization expressed the outbreak of COVID-19 as an international public health emergency [2], [3]. Over time, the disease has spread to all countries and by July 11, 2020 about 12.6 million and 642,000 people around the world have suffered and died from the disease, respectively [4]. At present, the highest cases of COVID-19 are in the United States, Brazil, India, Russia, Peru, Chile, Spain, Mexico, United Kingdom, and Iran, respectively [4], [5]. Furthermore, Iran is the seventh country in terms of the deaths due to disease [5]. The first case of COVID-19 in Iran was reported on February 19, 2020, and at the time of this paper (July 11, 2020), 255,117 cases and 12,635 deaths have been occurred in Iran [5], [6]. The daily increase of morbidity and mortality due to the disease has detrimental effects on the economies especially the health-care systems [7]. Over COVID-19 pandemic, the demand for personal protective equipment (PPE) such as facemasks and disinfectants has been dramatically increased [8], [9]. The lack of PPE has caused great concern and has endangered the public health of human [10]. On the other hand, no specific drug or vaccine has already been made to treat the disease [2], [11]. Therefore, following the protocols and guidelines for the prevention and control of COVID-19 is the most important way to deal with this disease [2].

COVID-19 is highly contagious and can be directly transmitted from person to person through direct contact (less than $1.5 \mathrm{~m}$ distance) or indirectly contact 
with an infected surface [2], [12]. According to the World Health Organization, more than $80 \%$ of COVID-19 cases are in mild state and can be cured without medical intervention. About $20 \%$ of the individuals also show severe symptoms of the disease [13]. The early symptoms of the disease include fever, dry cough, fatigue and bruising, and in rare cases, headache, and diarrhea [2]. The incubation period of 1-14 days is also reported for the disease [14], [15], [16]. No exposure to SARS-CoV-2 is the most important way to prevent the disease [17]. The main approaches including frequent washing of hands with soap and water, wearing a facemask and quarantine of COVID-19 suspicious people can be applied to prevent the disease [17], [18]. The knowledge and attitude of people toward COVID-19 will play a significant role in preventing and subsequently reducing the morbidity and mortality of the disease [19]. The findings of similar studies during SARS (2003) and MERS (2014) outbreaks showed that people's knowledge and attitudes played a substantial role in their preventive behaviors [19], [20], [21]. The assessment of people's knowledge, attitude, and practice levels toward COVID-19 can be a very important step to assess the health educational needs and planning the effective interventions to fight the disease [22], [23].To the best of our knowledge, the present study is carried out, for the $1^{\text {st }}$ time, to assess the knowledge, attitude, practice, and fear of the general Iranian population regarding COVID-19.

\section{Methods}

\section{Study sampling}

A total of 558 individuals, from all over Iran, participated in this cross-sectional study. The online convenience sampling was performed from March 27 to April 10, 2020. The questionnaire link was sent to people through WhatsApp and Telegram, the most popular social applications in Iran. The sample size was estimated using online software (Raosoft sample size calculator: http://www.raosoft.com/samplesize.html). The estimated sample size was 383 with a considered margin of error of $5 \%$ and a $95 \%$ confidence interval. However, to increase the reliability of the results, due to the high volume of the population size, the sample size of 558 was considered. Out of 1131 visitors, 637 individuals answered the questionnaire and due to the incomplete answers of 79 people, the data of 558 respondents were finally analyzed. The explanations related to the questionnaire as well as the conscious participation form were sent to the individuals along with the questionnaire link. The individuals with smartphones with WhatsApp or Telegram apps and internet access could participate in the study. The individuals should also have at least some basic literacy and interest to participate in the study. People under the age of 18 years and those who incomplete the questionnaire were excluded from the study. The average time to answer the questionnaire was about $10 \mathrm{~min}$.

\section{Measurements}

A 50-item researcher-made online questionnaire was used to collect data in five sections. The first part evaluated the subjects' demographic information such as age, gender, education level, marital status, job status, family economic status, and place of residence.

The second part assessed the participants knowledge on COVID-19 with 12 items (e.g., a dry cough is a common symptom of COVID-19). The answers in this section were scored as $Y e s=2$, I don't know=1, and $\mathrm{No}=0$. The total knowledge scores ranged from 0 to 24 , which higher scores indicated a higher level of knowledge. According to the median split method [24], the participants with a total score of lower and higher than 18 (median) were considered as inadequate and adequate knowledge, respectively.

The third section determined the individuals' attitude on COVID-19 using 12 items (e.g., If I don't go to the crowded places, I reduce the risk of COVID-19). The answers of this section were scored by a five-point Likert scale from completely disagree $=1$ to completely agree $=5$. The total attitude scores ranged from 12 to 60 , which higher scores represented a more appropriate attitude.

The fourth section estimated the participants' practice related to COVID-19 with 18 items (e.g., mask wearing in the presence of the suspected persons or attendance at crowded places). The answers in this section were also according to a 5-part Likert scale from never $=1$ to always $=5$.

The fifth section was applied to assess people's fear of COVID-19 with one question (how much do you fear of COVID-19?). The answers to this question were based on a 5-part Likert scale from never=1 to so much $=5$. The total practice scores ranged from 18 to 90 , which higher scores showed a more suitable practice.

The subjects' responses of attitude and practice items were divided into three categories as follow. The scores $<50 \%, 50-75 \%$, and over $75 \%$ were classified as weak, moderate, and good responses, respectively [25]. The studied parameters of knowledge, attitude, and practice in the questionnaire are shown in Table 1.

The content validity of the questionnaire was qualitatively evaluated using the opinions of six health education and health promotion specialists. The corrective recommendations of the specialists were 
Table 1: Relative frequency (\%) of participants' answers to questionnaire items ( $n=558)$

\begin{tabular}{|c|c|c|c|c|c|}
\hline Items No & Answers (\%) & & & & \\
\hline Knowledge & Yes $^{*}$ & No & & I don't know & \\
\hline 1. The use of facemask is essential for healthy people & 43.7 & 47.1 & & 9.2 & \\
\hline 2. It is essential to use a facemask when you are exposed to a sick or symptomatic person & 82.2 & 4.3 & & 13.5 & \\
\hline 3. Wearing filtered masks such as the N95 mask is suitable for infected or suspected people & 57.9 & 31.4 & & 10.7 & \\
\hline 4. The surgical mask can be used for a maximum time of $2 \mathrm{~h}$ & 62.2 & 18.8 & & 19 & \\
\hline 5. Industrial alcohol can kill the coronavirus & 28.2 & 55.1 & & 16.7 & \\
\hline 6. The minimum distance of $1 \mathrm{~m}$ is suitable against infected or suspected people & 70.8 & 25.4 & & 3.8 & \\
\hline $\begin{array}{l}\text { 7. For disinfection of surfaces such as bathroom and toilet floors, bleach solution with a } \\
\text { concentration of a-half percent is suitable }\end{array}$ & 41.8 & 22.9 & & 35.2 & \\
\hline 8. The improvement of personal hygiene is the most important way to prevent COVID-19 & 88.9 & 10.9 & & 3.1 & \\
\hline 9. Fever is one of the most common symptoms of COVID-19 & 92 & 5.6 & & 2.4 & \\
\hline 10. Runny nose is a common symptom of COVID-19 & 24 & 64.9 & & 11.1 & \\
\hline 11. Dry cough is one of the most common symptoms of COVID-19 & 96.2 & 1.7 & & 2.1 & \\
\hline 12. Fatigue is one of the most common symptoms of COVID-19 & 69.3 & 19.2 & & 11.5 & \\
\hline Attitude & Completely agree & Agree & Neutral & Disagree & Completely disagree \\
\hline 1. I am at risk for COVID-19 & 22.3 & 38.1 & 22.2 & 11.8 & 5.6 \\
\hline 2. My family are at risk for COVID-19 & 19.5 & 41.1 & 20.6 & 14.4 & 4.4 \\
\hline 3. If I do not observe personal hygiene, I can infect my family with COVID-19 & 52.3 & 38.9 & 3.1 & 4.3 & 1.4 \\
\hline 4. I'm worried about getting COVID-19 & 38.7 & 43.2 & 12.9 & 4.3 & 0.9 \\
\hline 5. Because COVID-19 is an unknown and mysterious disease, I am afraid of it & 41.1 & 36.7 & 14.5 & 6.6 & 1.1 \\
\hline 6. Hearing the news about COVID-19 mortality scares me & 28.7 & 36.9 & 18.5 & 12.5 & 3.4 \\
\hline 7. If I don't attend crowded places, I reduce the risk of COVID-19 & 66.3 & 28.3 & 2.3 & 3.1 & 0 \\
\hline 8. Staying at home reduces the risk of COVID-19 & 68.6 & 26.3 & 4.7 & 0 & 0.4 \\
\hline $\begin{array}{l}\text { 9. If I don't travel during the COVID-19 outbreak, I will prevent myself and my family from the } \\
\text { disease. }\end{array}$ & 65.3 & 27.2 & 3.8 & 2.4 & 0.2 \\
\hline 10. I'm tired to stay at home because of COVID-19 & 39.1 & 26.2 & 17.6 & 10.4 & 6.7 \\
\hline 11. It is difficult to provide the sanitary items such as facemask and gloves & 47 & 37.1 & 8.4 & 5 & 2.5 \\
\hline 12. The information received about COVID-19 is very different and confusing & 34.6 & 23.8 & 16.7 & 17.7 & 7.2 \\
\hline Practice & Always & Often & Some time & Seldom & Never \\
\hline 1. Wear a mask whenever confronting with a person suspected of COVID-19 & 43.4 & 28.7 & 12.4 & 9.8 & 5.7 \\
\hline 2. Wear gloves whenever contacting with contaminated objects and surfaces & 29.4 & 22 & 27.4 & 12.2 & 9 \\
\hline 3. Avoid hand contact with eyes, nose and mouth & 35.4 & 27.9 & 22.9 & 8.5 & 5.3 \\
\hline 4. Disinfect the home environment & 29.7 & 21.3 & 31.2 & 11.9 & 5.9 \\
\hline 5. Disinfect personal belongings & 33.4 & 23.7 & 24.4 & 12.8 & 5.7 \\
\hline 6. Frequent handwashing with soap and water & 63.1 & 25.7 & 9.8 & 0.9 & 0.5 \\
\hline 7. Maintain a distance of at least $1 \mathrm{~m}$ with suspected people & 51 & 27.2 & 18 & 2.9 & 0.9 \\
\hline 8. Cover your mouth and nose when you cough or sneeze & 60.6 & 26 & 12 & 0.9 & 0.5 \\
\hline 9. Avoid contact with animals & 60.9 & 24.2 & 8.1 & 3.4 & 3.4 \\
\hline 10. Avoid hand shaking with others & 79.1 & 12.4 & 7.3 & 0.7 & 0.5 \\
\hline 11. Using healthy and nutritious diet & 22.1 & 23 & 31.7 & 17.3 & 5.9 \\
\hline 12. Avoid unnecessary presence in the medical centers & 74.7 & 4.8 & 7.4 & 5 & 8.1 \\
\hline 13. Avoid smoking & 32.2 & 18.1 & 22.2 & 15.4 & 12.1 \\
\hline 14. Dispose of used handkerchiefs, gloves or masks in a hygienic and safe manner & 43.3 & 23.4 & 17 & 9.5 & 6.8 \\
\hline 15. Natural ventilation through windows & 36.9 & 23.7 & 22.8 & 10.5 & 6.1 \\
\hline 16. Stay at home & 49.2 & 22 & 18.5 & 8 & 2.3 \\
\hline 17. Avoid crowded places & 53.1 & 28.2 & 11.9 & 4.3 & 2.5 \\
\hline 18. Avoid unnecessary travel & 65 & 17 & 10.5 & 7.1 & 0.4 \\
\hline
\end{tabular}

18. Avoid unnecessary trave

${ }^{\star}$ For knowledge items no 3,5 , and 10, the correct answer=No.

carried out on the simplicity, appropriateness, ambiguity, and items necessity and scoring. The reliability of the knowledge, attitude, and practice scales was determined by assessing the internal consistency of the items for each section and the results are presented in Table 2.

Table 2: Means, standard deviations, and internal consistency of knowledge, attitude, and practice toward COVID-19

\begin{tabular}{|c|c|c|c|c|c|}
\hline Variables & Mean number (\%) & $\mathrm{SD}^{\dagger}$ & Items & Score range & Internal consistency \\
\hline Knowledge & 18.11 & 2.24 & 12 & $0-24$ & 0.64 \\
\hline Adequate & $320(56.5)$ & & & & \\
\hline Inadequate & $243(43.5)$ & & & & \\
\hline Attitude & 48.96 & 5.07 & 12 & $12-60$ & 0.83 \\
\hline Weak & $23(4.12)$ & & & & \\
\hline Moderate & $241(43.18)$ & & & & \\
\hline Good & $294(52.68)$ & & & & \\
\hline Practice & 71.56 & 8.56 & 18 & $18-90$ & 0.92 \\
\hline Weak & $26(4.66)$ & & & & \\
\hline Moderate & $243(43.54)$ & & & & \\
\hline Good & $397(51.80)$ & & & & \\
\hline
\end{tabular}

\section{Data analysis}

The data were analyzed by SPSS software version 19. Descriptive statistics, one-way analysis of variance, independent sample t-test, and bivariate Pearson's correlation were used to analyze the data. $p<0.05$ was considered statistically significant in the present study.

\section{Results}

The study was carried out on 558 participants with a mean age of $33.3 \pm 10.01$ years. As listed in Table $3,61.3 \%, 57.9 \%$, and $81.0 \%$ of the subjects were women, married, and living in urban areas, respectively. Table 3 also shows the comparison of mean and standard deviation of knowledge, attitudes, and practice scores of the subjects related to COVID-19 based on demographic variables. As it can be seen, the knowledge of people living in the city was significantly higher than the rural population $(p=0.018)$. The attitudes of married $(p=0.001)$, employees, and housewives were also significantly higher than other people $(p=0.006)$. The individuals with low-income had a weaker practice than others $(p=0.001)$. The participants' knowledge related to the importance of personal hygiene $(88.9 \%)$, the necessity of using a facemask in contact with infected or suspicious people $(82.2 \%)$, and the symptoms of the COVID-19 (76.8\%) were at a high level. However, their knowledge about contaminated surfaces disinfection procedure $(41.8 \%)$, and the importance of using facemasks for healthy people $(43.7 \%)$ was lower. The highest level of subjects' attitude was 
Table 3: Comparison of mean scores and standard deviation of knowledge, attitude, and practices of the participants regarding to COVID-19 based on socio-demographic characteristics

\begin{tabular}{|c|c|c|c|c|c|c|c|}
\hline Characteristics & Number (\%) & Knowledge Mean $\pm \mathrm{SD}^{\dagger}$ & $p$-value & Attitude Mean \pm SD & p-value & Practice Mean \pm SD & p-value \\
\hline \multicolumn{8}{|l|}{ Gender } \\
\hline Male & $216(38.7)$ & $18.20(2.07)$ & \multirow[t]{2}{*}{0.439} & $48.52(5.15)$ & \multirow[t]{2}{*}{0.108} & $71.0(8.62)$ & \multirow[t]{2}{*}{0.223} \\
\hline Female & $342(61.3)$ & $18.16(2.34)$ & & $49.24(5.01)$ & & $71.92(8.53)$ & \\
\hline \multicolumn{8}{|l|}{ Marital status } \\
\hline Single & $231(41.4)$ & $18.26(2.21)$ & \multirow[t]{3}{*}{0.153} & $47.36(5.33)$ & \multirow[t]{3}{*}{0.001} & $71.59(8.71)$ & \multirow[t]{3}{*}{0.149} \\
\hline Married & $323(57.9)$ & $17.90(2.28)$ & & $49.72(4.77)$ & & $71.65(8.44)$ & \\
\hline Divorced/widowed & $4(0.7)$ & $18.75(0.50)$ & & $49.54(2.51)$ & & $63.25(8.51)$ & \\
\hline \multicolumn{8}{|l|}{ Educational level } \\
\hline Primary school & $13(2.3)$ & $17.69(2.95)$ & \multirow[t]{3}{*}{0.165} & $46.92(3.63)$ & \multirow{3}{*}{0.081} & $70.15(5.24)$ & \multirow[t]{3}{*}{0.167} \\
\hline Secondary school & $55(9.9)$ & $18.52(2.04)$ & & $48.87(4.72)$ & & $69.63(6.45)$ & \\
\hline University graduated/students & $490(78.8)$ & $18.08(2.24)$ & & $49.03(5.14)$ & & $71.82(7.52)$ & \\
\hline \multicolumn{8}{|l|}{ Occupational situation } \\
\hline Householder & $112(20.1)$ & $18.11(2.59)$ & \multirow{6}{*}{0.211} & $49.93(4.36)$ & \multirow{6}{*}{0.006} & $72.89(7.07)$ & \multirow{6}{*}{0.093} \\
\hline Employee & $190(34.1)$ & $18.14(1.97)$ & & $51.49(4.48)$ & & $71.72(9.25)$ & \\
\hline Self-employment & $72(12.9)$ & $17.69(2.28)$ & & $49.02(5.13)$ & & $70.41(8.07)$ & \\
\hline Laborer & $12(2.2)$ & $18.25(2.04)$ & & $48.33(5.29)$ & & $69.16(10.32)$ & \\
\hline Retired & $154(27.6)$ & $18.77(2.71)$ & & $48.05(5.14)$ & & $73.16(7.13)$ & \\
\hline Unemployed & $18(3.2)$ & $18.19(2.22)$ & & $48.21(6.56)$ & & $70.96(7.87)$ & \\
\hline \multicolumn{8}{|l|}{ Place of residence } \\
\hline City & $491(81.0)$ & $18.21(2.16)$ & \multirow[t]{2}{*}{0.018} & $48.84(5.16)$ & \multirow[t]{2}{*}{0.091} & $71.64(8.32)$ & \multirow[t]{2}{*}{0.215} \\
\hline Village & $67(12.0)$ & $17.36(2.68)$ & & 49.88 (4.28) & & $71.02(9.91)$ & \\
\hline \multicolumn{8}{|l|}{ Socioeconomic status } \\
\hline High & $187(33.5)$ & $18.13(2.18)$ & \multirow[t]{3}{*}{0.671} & $48.92(4.88)$ & \multirow[t]{3}{*}{0.124} & $72.90(8.59)$ & \multirow{3}{*}{0.001} \\
\hline Intermediate & $310(55.6)$ & $18.08(2.12)$ & & $49.06(4.95)$ & & $71.81(7.87)$ & \\
\hline Low & $61(10.9)$ & $18.04(1.27)$ & & $48.31(5.16)$ & & $66.43(8.52)$ & \\
\hline
\end{tabular}

related to the role of social distancing (94.6\%), staying at home $(94.5 \%)$, and personal hygiene $(91.2 \%)$. The low levels of attitude were also associated with the access to PPE (84.1\%), the psychological effects of COVID-19 (65.3\%), and the information related to COVID-19 (58.4\%). Furthermore, the highest levels of preventive behaviors were related to avoiding hand shaking with others $(91.5 \%)$, washing hands frequently $(88.8 \%)$, and covering the mouth and nose when sneezing or coughing $(86.6 \%)$. The behaviors such as following a healthy and nutritious diet (45.1\%), wearing gloves when in contact with contaminated surfaces (51.4\%), and avoiding smoking (52.3\%) were reported to be less common (Table 1). As listed in Table 2, $56.5 \%$ of the participants had adequate knowledge, $52.6 \%$ had a good attitude, and $51.8 \%$ had appropriate practice related to COVID-19. The findings of Pearson's correlation test showed the positive and significant correlation between knowledge and attitude $(r=0.114, p=0.026)$, knowledge and practice $(r=0.224, p=0.011)$, as well as attitude and practice $(r=0.281, p=0.005)$. In addition, the results showed that $28.3 \%, 22 \%$, and $32.8 \%$ of the subjects were so much, much, and somewhat afraid of the COVID-19, respectively (Figure 1).

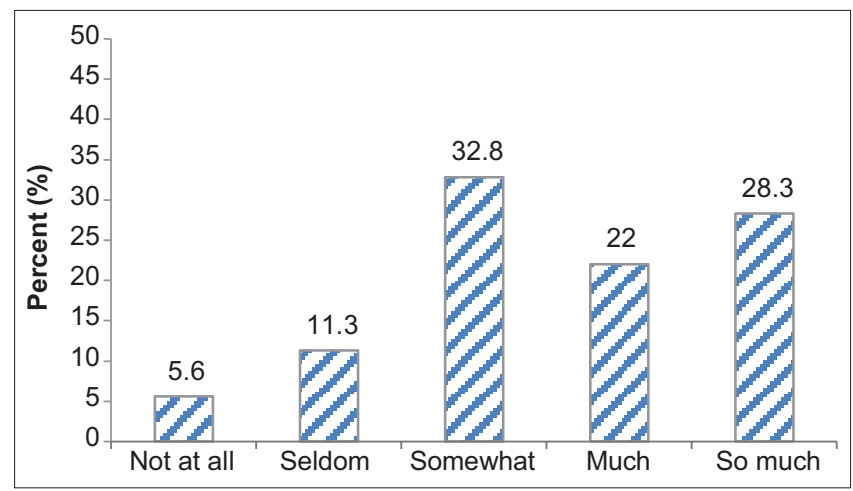

Figure 1: Relative frequency (\%) of participants' fear of COVID-19 $(n=558)$

\section{Discussion}

The aim of this study was to investigate the knowledge, attitude, and practice toward COVID19 among a sample of Iranian people. The findings showed that $56.5 \%$ of the Iranians had adequate knowledge related to the COVID-19. The participants had sufficient knowledge about personal hygiene, the symptoms of COVID-19, and social distancing. However, their knowledge on facemask wearing as well as the correct use of disinfectants was not enough. A literature review of similar studies showed that the knowledge, attitudes, and behaviors of the people vary according to the sample type and the time of the study. In a study by Wolf et al. (2020), the knowledge of adults with underlying disease in the United States (U.S) on COVID-19 was reported to be insufficient [26]. In a study by Johnson and Hariharan (2017), a significant proportion of Trinidad and Tobago people did not have sufficient knowledge about the H1N1 flu and its prevention strategies [27]. Furthermore, in a study of Srichan et al. (2020), the knowledge of Thai people about COVID-19 was poorly reported [28]. In several other studies, the knowledge level of Chinese students [29], Iranian medical students [10], healthcare workers in Vietnam [2], Chinese health workers [30], and Indian dentists [31] about COVID-19 and ways to prevent and control the disease was appropriate. In a study by Roy et al. (2020), Indians also had moderate knowledge about the SARS-CoV-2 infection and its symptoms, but their knowledge on ways of preventing the disease was satisfactory [9].

In the present study, the individuals' knowledge on COVID-19 prevention was positively and significantly correlated with their practice. The findings showed that the improvement of people's knowledge on COVID-19 can increase their preventive behaviors for the disease. 
However, often high knowledge alone does not lead to optimal practice [32]. The prevention and control of COVID-19 are desirable when in addition to sufficient knowledge; there should be a favorable attitude toward preventive measures against this disease [33].

In the present study, most of the Iranian people had moderate or good attitude toward COVID-19 prevention. Most of the individuals had a good understanding of the COVID-19 risk. They also perceived the importance of personal hygiene to prevent COVID-19 and believed to stay at home and avoid crowded places. However, some individuals believed that access to PPE was difficult. They also expressed that the information received about COVID-19 was confusing and the disease had a negative influence on their mental health. The findings of similar studies showed that there was a good attitude among different types of groups in society in various countries toward COVID-19 [2], [10], [19], [29], [30], [31]. However, study of Taghrir et al. (2020) expressed a moderate attitude toward COVID-19 prevention among the Iranian medical students [10]. Furthermore, study of Srichan et al. (2020) reported that one third of Thai people had a weak attitude about the disease [28]. In the present study, about $47 \%$ of the subjects had a weak or moderate attitude toward COVID-19. Since the announcement of COVID-19 outbreak in Iran, the Ministry of Health and Medical Education (MOHME) has developed extensive instructions to fight the disease. There have also been several national campaigns to combat the disease in Iran, such as "We defeat COVID-19" and "Stay at Home" [34], [35], [36]. The MOHME has also implemented a variety of training programs in cooperation with the Iran Broadcasting to fight COVID-19. The findings of the present study and also similar studies in Iran [10], [30], [31] showed that the Iranian people have successfully followed the MOHME guidelines for prevention and control of COVID-19. However, some Iranians still do not have the acceptable knowledge, attitude, and practice to deal with the disease. The reality is that in addition to scientific and authoritative information and instructions about COVID-19, unfortunately the misinformation, misconceptions, and unscientific procedures have also been spread in the community, especially by virtual social networks [37], [38]. The misconceptions such as rubbing viola and sesame oils on the body, drinking camel urine, gargling with salt water or mouthwash, using a hair dryer, and drinking alcohol may prevent people from following the correct instructions [37], [39]. On the other hand, due to the unknown nature of some behavioral aspects of COVID-19, the authoritative scientific sources may also provide confusing information, such as the necessity or non-necessity of wearing a facemask by healthy people, to the general public [40], [41].

The internet and virtual social networks have been reported as the most important source of information for people about COVID-19 [38], [39]. The virtual social networks, despite their great contribution to the rapid circulation of scientific information, can be a place to spread misinformation and misconceptions [37], [39], [42]. Therefore, it is necessary for people that are aware of the reliable and scientific sources toward COVID-19 and, on the other hand, to avoid spreading misinformation related to the disease [42]. To do this, the MOHME needs to have a scientific channel about the COVID-19 in virtual social networks and provides health education programs, like the World Health Organization that works with social media, including Facebook, Twitter, and WhatsApp, to provide accurate information about COVID-19 [40].

According to the presentstudy, most participants had a good practice about COVID-19. About $48 \%$ of the individuals also had moderate or weak practice. The subjects in the study had good behaviors such as frequent hand washing, social distancing, wearing masks, staying at home, and avoiding going to crowded places. However, the behaviors such as wearing gloves, disinfection of home and personal belongings, as well as air conditioning at home were reported at a lower level. The knowledge and attitude of the subjects were directly and significantly related to their practice in relation to COVID-19 prevention and control. Moreover, the weak knowledge and attitude toward some of the facts and strategies about the COVID-19 prevention led to poorer practice. The findings of various studies such as our research reported good practice of the subjects on the protective behavior against COVID-19 [10], [19], [28], [29], [30], [31].

The participants' knowledge, attitudes, and practice were partly influenced by the demographic factors. The comparison of the knowledge score of the individuals with respect to the demographic variables showed that the knowledge level of people living in urban areas was significantly higher than in rural areas. People in rural areas of Iran have lower education and literacy levels [43], [44]; therefore, they may be more affected by incorrect information related to COVID-19. On the other hand, the quantity and quality of internet access and penetration in the rural areas of Iran are weaker than urban ones [45], [46]. Because of the fundamental role of the internet and virtual social networks to enhance people's information about COVID-19 [38], [39], the weaker knowledge of the people living in the rural areas was expected. The married subjects had a more suitable attitude toward the COVID-19 than single people. Marital status is known as one of the social determinants on health [47]. The previous studies have shown that married people are more likely to engage in health behaviors and they have a high level of health [48], [49], [50]. The married people have a positive attitude toward health behaviors, due to less stress and more social support, especially from their family. Marital status may provide more opportunities for men to progress their health than 
women [47], [51]. The employees also had a significantly more positive attitude toward COVID-19 prevention and control. The employees may have more opportunities to learn about the disease than other occupations. One reason for this is that the employees in Iran have often higher level of education and health literacy [52], [53]. The individuals with moderate and good social level and economic well-being had significantly better practice on COVID-19 prevention and control than the low level people. Zhong et al. (2020) also reported that people with high socioeconomic status had better knowledge, attitude, and practice toward COVID-19 [19]. Srichan et al. (2020) reported that people with higher incomes had a better practice on COVID-19 prevention [28]. The weaker practice of the lower incomes people in the society about COVID-19 prevention can be analyzed from several aspects. First, the high demand of PPE (gloves, facemasks, and disinfectants) during the disease outbreak in Iran led to a shortage of these items and as a result, the prices of them were significantly increased. Therefore, it became more difficult for the lower incomes people to provide these items. Second, most of low-income people in the society are worker or self-employed who do not have a steady income and must work daily. Therefore, follow the instructions of "stay at home" for a long time was the important barrier for these people. Eventually, these people were forced to ignore the social distancing instruction to leave the home.

\section{Study limitations}

The present study was first carried out to assess the knowledge, attitude, and practice levels of the general population in Iran toward COVID-19. However, this research had several limitations. First, the subjects often had a university degree, while in Iran about $20 \%$ of the population over the age of 18 years is academics [54] Therefore, it is possible that the levels of knowledge, attitude, and practice reported in this study were higher than of their actual values in the general population of Iran. Second, the study was conducted on adults ( $\geq 18$ years). Third, only literate people were considered in the study. Therefore, it is not possible to generalize the findings to illiterate people. Fourth, because the online study was conducted, people who did not have access to the internet, as well as smartphones, could not participate in the study.

\section{Conclusion}

The findings of the study showed that the most of subjects had adequate knowledge and a good attitude and practice toward COVID-19. The participants performed well on COVID-19 protective behaviors including handwashing, wearing facemask, social distancing, and avoiding going to crowded places. However, the behaviors such as wearing gloves, disinfection of home and personal belongings, as well as air conditioning at home were reported at a lower level. The extensive implementation of health education programs to raise knowledge about COVID-19 and also motivate people to do preventive behaviors is critical. In addition, to increase the effectiveness of health education interventions, it is necessary to consider the demographic and socio-economic characteristics of the target groups and their specific educational needs.

\section{Acknowledgment}

The authors acknowledge the Research and Technology Deputy of Ilam University of Medical Sciences, Iran, for financial supporting the present study. This study was reviewed and proved by the Research Ethics Committee of the university (IR. MEDILAM.REC.1399.038).

\section{References}

1. Carlos WG, Cruz CS, Cao B, Pasnick S, Jamil S. Nove Wuhan (2019-nCoV) coronavirus. Am J Respir Crit Care Med. 2020;201(4):7-8. https://doi.org/10.1164/rccm.2014p7 PMid:32004066

2. Giao H, Han NT, Van Khanh T, Ngan VK, Van Tam V, Le An P. Knowledge and attitude toward COVID-19 among healthcare workers at district 2 hospital, Ho Chi Minh city. Asian Pac J Trop Med. 2020;1:13.

3. Zhu N, Zhang D, Wang W, Li X, Yang B, Song J, et al. A novel coronavirus from patients with pneumonia in China, 2019. N Engl J Med. 2020;382(8):727-33.

PMid:31978945

4. World Health Organization. Coronavirus Disease (COVID-19) Outbreak Situation. Geneva: World Health Organization; 2019. Available from: https://www.who.int/emergencies/diseases/ novel-coronavirus-2019. [Last accessed on 2020 Jun 01].

5. Iranian Ministry of Health and Medical Education. COVID-19 Daily Epidemiology Journal; 2020. Available from: http://www. corona.behdasht.gov.ir/files/site1/files/factsheet_24-0126-Fa. pdf. [Last accessed on 2020 Apr 14].

6. Takian A, Raoofi A, Kazempour-Ardebili S. COVID-19 battle during the toughest sanctions against Iran. Lancet. 2020;395:1035-6. https://doi.org/10.1016/s0140-6736(20) 30668-1

PMid:32199073

7. Fernandes N. Economic Effects of Coronavirus Outbreak (COVID-19) on the World Economy. Spain: University of Navarra; 2020.

8. World Health Organization. Rolling Updates on Coronavirus Disease (COVID-19). Geneva: World Health Organization; 2020c. Available from: https://www.who.int/emergencies/ 
diseases/novel-coronavirus-2019/events-as-they-happen. [Last accessed on 2020 Apr 28]

9. Roy D, Tripathy S, Kar SK, Sharma N, Verma SK, Kaushal V. Study of knowledge, attitude, anxiety and perceived mental healthcare need in Indian population during COVID-19 pandemic. Asian J Psychiatry. 2020;51:102083. https://doi. org/10.1016/j.ajp.2020.102083

PMid:32283510

10. Kwok KO, Li KK, Chan HH, Yi YY, Tang A, Wei WI, et al. Community Responses during the Early Phase of the COVID-19 Epidemic in Hong Kong: Risk Perception, Information Exposure and Preventive Measures. medRxiv; 2020. https://doi. org/10.1101/2020.02.26.20028217

11. Centers for Disease Control and Prevention. Coronavirus Disease 2019 (COVID-19). Atlanta, Georgia: Centers for Disease Control and Prevention; 2020. Available from: https:// www.cdc.gov/coronavirus/2019-ncov/about/transmission.html. [Last accessed on 2020 May 03]. https://doi.org/10.1093/ofid/ ofv131.60

12. World Health Organization. WHO Director-General's Opening Remarks at the Mission Briefing on COVID-19. Geneva: World Health Organization; 2020. Available from: https://www.who.int/dg/ speeches/detail/who-director-general-s-opening-remarks-at-themission-briefing-on-covid-19. [Last accessed on 2020 May 01]. https://doi.org/10.1093/ww/9780199540884.013.u44226

13. Peng $X, X u X, L i$, Cheng L, Zhou X, Ren B. Transmission routes of 2019-nCoV and controls in dental practice. Int J Oral Sci. 2020;12(1):9. https://doi.org/10.1038/s41368-020-0075-9

14. Huang $C$, Wang $Y$, Li X, Liu L, Yan X, Wang J, et al. Clinical features of patients infected with 2019 novel coronavirus in Wuhan, China. Lancet. 2020;395(10223):497-506. https://doi. org/10.1016/s0140-6736(20)30183-5

15. Wang, D, Hu B, Hu C. Clinical characteristics of 138 hospitalized patients with 2019 novel coronavirus-infected pneumonia in Wuhan, China. JAMA. 2020;323:1061-9. https://doi. org/10.1001/jama.2020.1585

PMid:32031570

16. Alzoubi $\mathrm{H}$, Alnawaiseh $\mathrm{N}$, Al-Mnayyis MA, Lubada AA, Al-Shagahin H. COVID-19-knowledge, attitude and practice among medical and non-medical university students in Jordan. J. Pure Appl Microbiol. 2020;14(1):17-24. https://doi. org/10.22207/jpam.14.1.04

17. Riou J, Althaus CL. Pattern of early human-to-human transmission of Wuhan 2019 novel coronavirus (2019nCoV), December 2019 to January 2020. Euro Surveill. 2020;25(4):2000058. https://doi.org/10.2807/1560-7917. es.2020.25.4.2000058 PMid:32019669

18. Zhong BL, Luo W, Li HM, Zhang QQ, Liu XG, Li WT, et al. Knowledge, attitudes, and practices towards COVID-19 among Chinese residents during the rapid rise period of the COVID-19 outbreak: A quick online cross-sectional survey. Int J Biol Sci. 2020;16(10):1745-52. https://doi.org/10.7150/ijbs.45221 PMid:32226294

19. Person B, Sy F, Holton K, Govert B, Liang A, National Center for Inectious Diseases SCOT. Fear and stigma: The epidemic within the SARS outbreak. Emerg Infect Dis. 2004;10(2):35863. https://doi.org/10.3201/eid1002.030750 PMid: 15030713

20. Tao N. An analysis on reasons of SARS-induced psychological panic among students. J Anhui Inst Educ. 2003;21:78-9.

21. Mirzaei A, Esmaeili F, Jalilian M. Predictors of complementary feeding in infants aged 6 to 18 months: An application of health belief model. Sri Lanka J Child Health. 2020;49(1):48-53. https:// doi.org/10.4038/sljch.v49i1.8898

22. Mirzaei A, Ghofranipour F, Ghazanfar ZI. School children's breakfast consumption: An educational intervention based on social cognitive theory. Ann Trop Med Public Health. 2018;2(1):SP36. https://doi.org/10.9734/jammr/2019/v29i430080

23. Al-Lela OQ, Bahari MB, Salih MR, Al-Abbassi MG, Elkalmi RM, Jamshed SQ. Factors underlying inadequate parents' awareness regarding pediatrics immunization: Findings of cross-sectional study in Mosul-Iraq. BMC Pediatr. 2014;14(1):29. https://doi. org/10.1186/1471-2431-14-29

24. Kashfi M, Eslahi M, Rakhshani $T$, Hashemi $H$, Baqeri $P$, Sharafi M. A survey of knowledge, attitude and performance of people of fasa on segregation of household solid wastes, Fasa, Iran, 2017. J Health Sci Surveill Syst. 2018;6(1):40-5.

25. Wolf MS, Serper M, Opsasnick L, O'Conor RM, Curtis LM, Benavente JY, Wismer G, Batio S, Eifler M, Zheng P, Russell A. Awareness, attitudes, and actions related to COVID-19 among adults with chronic conditions at the onset of the US outbreak: A cross-sectional survey. Ann Intern Med. 2020;173(2):100-9. https://doi.org/10.7326/m20-1239

PMid:32271861

26. Johnson EJ, Hariharan S. Public health awareness: Knowledge, attitude and behaviour of the general public on health risks during the H1N1 influenza pandemic. J Public Health. 2017;25:333-7. https://doi.org/10.1007/s10389-017-0790-7

27. Srichan $P$, Apidechkul $T$, Tamornpark R, Yeemard F, Khunthason S, Kitchanapaiboon S, et al. Knowledge, attitude and preparedness to respond to the 2019 novel coronavirus (COVID-19) among the bordered population of Northern Thailand in the early period of the outbreak: A cross-sectional study. SSRN Electron J. 2020;1:3546046. https://doi.org/10.2139/ ssrn.3546046

28. Peng $\mathrm{Y}$, Pei $\mathrm{C}$, Zheng $\mathrm{Y}$, Wang J, Zhang $\mathrm{K}$, Zheng Z, et al Knowledge, Attitude and Practice Associated with COVID-19 among University Students: A Cross-sectional Survey in China. China: Fourth Military Medical University; 2020. https://doi. org/10.21203/rs.3.rs-21185/v1

29. Taghrir MH, Borazjani R, Shiraly R. COVID-19 and Iranian medical students; a survey on their related-knowledge, preventive behaviors and risk perception. Arch Iran Med. 2020;23(4):249-54. https://doi.org/10.34172/aim.2020.06 PMid:32271598

30. Zhou M, Tang F, Wang Y, Nie H, Zhang L, You G, et al. Knowledge, attitude and practice regarding COVID-19 among health care workers in Henan, China. J Hosp Infect. 2020;105(2):183-7. https://doi.org/10.1016/j.jhin.2020.04.012 PMid:32278701

31. Kamate SK, Sharma S, Thakar S, Srivastava D, Sengupta K, Hadi AJ, et al. Assessing Knowledge, Attitudes and Practices of dental practitioners regarding the COVID-19 pandemic: A multinational study. Dent Med Probl. 2020;57(1):11-7. https:// doi.org/10.17219/dmp/119743

PMid:32307930

32. Mirzaei A, Nourmoradi H, Zavareh MS, Jalilian M, Mansourian M, Mazloomi S, et al. Food safety knowledge and practices of male adolescents in west of Iran. Open Access Maced J Med Sci. 2018;6(5):908. https://doi.org/10.3889/oamjms.2018.175 PMid:29875870

33. Glanz K, Rimer BK, Viswanath K, editors. Health Behavior and Health Education: Theory, Research, and Practice. Hoboken, New Jersey: John Wiley and Sons; 2008.

34. Ministry of Health and Medical Education. Health Education and Promotion Office. Available from: http://www.iec.behdasht.gov. ir. [Last accessed on 2020 May 01].

35. Nemati M, Ebrahimi B, Nemati F. Assessment of Iranian nurses knowledge and anxiety toward COVID-19 during the current outbreak in Iran. Arch Clin Infect Dis. 2020;15:In Press. https:// doi.org/10.5812/archcid.102848 
36. Raeisi A, Tabrizi JS, Gouya MM. IR of Iran national mobilization against COVID-19 epidemic. Arch Iran Med. 2020;23(4):216-9. https://doi.org/10.34172/aim.2020.01

37. Geldsetzer P. Knowledge and Perceptions of Coronavirus Disease 2019 among the General Public in the United States and the United Kingdom: A Cross-sectional Online Survey. medRxiv; 2020. https://doi.org/10.1101/2020.03.13.20035568

38. Husnayain A, Fuad A, Su EC. Applications of google search trends for risk communication in infectious disease management: A case study of COVID-19 outbreak in Taiwan. Int J Infect Dis 2020;95:221-3. https://doi.org/10.1016/j.jijd.2020.03.021

39. Qian M, Wu Q, Wu P, Hou Z, Liang Y, Cowling BJ, et al. Psychological Responses, Behavioral Changes and Public Perceptions during the Early Phase of the COVID-19 Outbreak in China: A Population Based Cross-sectional Survey. medRxiv; 2020. https://doi.org/10.1101/2020.02.18.20024448

40. Allahverdipour $\mathrm{H}$. Global challenge of health communication: Infodemia in the coronavirus disease (COVID-19) pandemic. J Educ Community Health 2020;7(2):65-7. https://doi. org/10.29252/jech.7.2.65

41. Zarocostas J. How to fight an infodemic. Lancet. 2020;395:(10225):676. https://doi.org/10.1016/s0140-6736 (20)30461-x PMid:32113495

42. Pennycook G, McPhetres J, Zhang Y, Rand D. Fighting COVID-19 misinformation on social media: Experimental evidence for a scalable accuracy nudge intervention. Psychol Sci. 2020;1:177.

43. Golboni F, Nadrian H, Najafi S, Shirzadi S, Mahmoodi H. Urban rural differences in health literacy and its determinants in Iran: A community-based study. Aust J Rural Health. 2018;26(2):98-105 https://doi.org/10.1111/ajr.123 PMid:29214687

44. Zahnd WE, Scaife SL, Francis ML. Health literacy skills in rural and urban populations. Am J Health Behav. 2009;33(5):550-7.
PMid: 19296745

45. Salmani B, Mohammadzadeh P, Zoolghadr H. Investigating the effect of economic factors on Internet diffusion in developing countries. Q J Appl Theories Econ. 2015;2(2):81-102.

46. Zarabi V, Khorasani IM, Maddah M. Predicting the Internet diffusion rate in Iran by providing a Fuzzy-diffusion model. J Technol Dev Manag. 2013;3:123-51.

47. Baheiraei A, Bakouei F, Mohammadi E, Montazeri A Hosseni M. The social determinants of health in association with women's health status of reproductive age: A populationbased study. Iran J Public Health. 2015;44(1):119. https://doi. org/10.1186/1742-4755-11-35

48. Koskenvuo M, Daprio J, Lonnqvist J, Sarna S. Social factors and the gender difference in mortality. Soc Sci Med. 1986;23:605-9. https://doi.org/10.1016/0277-9536(86)90154-1

49. Trovato F, Lauris G. Marital status and mortality in Canada. J Mar Fam. 1989;51:907-22.

50. Wyke S, Ford G. Competing explanations for associations between marital status and health. Soc Sci Med. 1992;34:523-32. https://doi.org/10.1016/0277-9536(92)90208-8

51. Ballantyne PJ. The social determinants of health: A contribution to the analysis of gender differences in health and illness. Scand J Public Health. 1999;27(4):290-5. https://doi.org/10.1177/1403 4948990270040101

52. Mirzaei A, Ramezankhani A, Ghaffari M, Jorvand R, Bazyar M, Momeni $\mathrm{K}$, et al. The effectiveness of health literacy based educational intervention on nutritional outcomes of elderly (Persian). Salmand. 2020;1:136.

53. Tavousi T, Mehrizi AH, Rafiefar SH, Solimanian A, Sarbandi F, Ardestani $\mathrm{M}$, et al. Health literacy in Iran: Findings from a national study. PAYESH. 2016;15(1):95-102.

54. Statistical Center of Iran. The Detailed Results of Iran. National Population and Housing Census; 2016. Available from: https:// www.amar.org.ir. [Last accessed on 2020 May 20] 